\title{
Condições hídricas e crescimento vegetal de culturas agrícolas importantes para comunidades indígenas do semiárido brasileiro ${ }^{1}$
}

\author{
Francimar da Silva Albuquerque ${ }^{2 *}$, Ennio Farias de França e Silva ${ }^{3}$, Pabrício Marcos Oliveira Lopes, \\ Geber Barbosa de Albuquerque Moura ${ }^{4}$, Alexsandro Oliveira da Silva ${ }^{5}$
}

$10.1590 / 0034-737 X 201865020001$

\begin{abstract}
RESUMO
A região semiárida brasileira caracteriza-se pela extrema variabilidade interanual da precipitação pluvial, de tal forma que o conhecimento do início e do fim da estação chuvosa contribui para evitar cultivos de lavouras antieconômicos e consequentes prejuízos. Objetivou-se com este trabalho relacionar as estimativas das condições hídricas com a estação de crescimento e com o desenvolvimento de culturas agrícolas importantes para as comunidades indígenas do semiárido nordestino, considerando-se três distintos cenários climatológicos. As estimativas da evapotranspiração potencial (ETP) mensal, para cada localidade, foram calculadas pelo método de Thornthwaite (1948) e transformadas em médias decendiais. As variáveis distribuição decendial da precipitação, ETP integral e metade da ETP foram utilizadas para caracterização da fase de crescimento do feijão-caupi, da mandioca e do milho, além da determinação dos períodos préúmido, úmido e pós-úmido. Na região do semiárido nordestino brasileiro, não é possível traçar um planejamento anual agrícola para cultivos de sequeiro em anos secos. Apenas para a localidade de Banzaê, BA-Quijingue, BA, nos cenários normal e chuvoso, foi possível prever épocas com menor probabilidade de risco para os cultivos, a partir da determinação do início, da duração e do final de cada subperíodo, bem como da estação de crescimento de cada cultura, que são 31/01 a 23/09 e 10/12 a 12/09 para o feijão-caupi, 31/01 a 01/11 e 10/12 a 21/10 para a mandioca, e 31/01 a 03/10 e 10/12 a 22/09 para o milho, na mesma ordem dos cenários de precipitação. Há uma grande variabilidade e irregularidade de períodos de dez dias de precipitação, ao longo do ano, nas localidades estudadas.
\end{abstract}

Palavras-chave: precipitação decendial; evapotranspiração; ciclo fenológico; índios.

\section{ABSTRACT}

\section{Water conditions and plant growth of important crops for indigenous communities of Brazilian semiarid}

The Brazilian semiarid region is characterized by extreme interannual rainfall variability, such that knowledge of the beginning and end of the rainy season contributes to avoiding uneconomic crops and consequent losses. The aim of this study was to relate the estimates of water conditions to the growth season and development of major crops for indigenous communities in the semiarid northeast, considering three different climatic scenarios. Monthly estimates of potential evapotranspiration (ETP) for each location were estimated through the method of Thornthwaite (1948) and transformed into 10-day averages. The variables 10-day distribution of precipitation, full ETP, and half ETP were used to characterize the growth phase of cowpea, cassava, and maize, along with the determination of pre-humid, humid, and post-humid periods. The results showed that, in the semiarid northeast region of Brazil, it is not possible to have an agricultural annual planning for rainfed crops in dry years. Only for the location of Banzaê, BA-Quijingue, BA, in

\footnotetext{
Submetido em 21/07/2017 e aprovado em 16/03/2018.

' Este trabalho é parte da tese de doutorado do primeiro autor

2 Fundação Nacional do Índio, Coordenação Regional Baixo São Francisco, Paulo Afonso, Bahia, Brasil. franciufrpe@gmail.com

${ }^{3}$ Universidade Federal Rural de Pernambuco, Departamento de Engenharia Agrícola, Recife, Pernambuco, Brasil. enio.fsilva@ufrpe.br

${ }^{4}$ Universidade Federal Rural de Pernambuco, Departamento de Agronomia, Recife, Pernambuco, Brasil. pabricio.lopes@ufrpe.br; geber.moura@ufrpe.br

Universidade Federal do Ceará, Centro de Ciências Agrárias, Departamento de Engenharia Agrícola, Fortaleza, Ceará, Brasil. alexsandro_oliveira01@hotmail.com

* Autor para correspondência: franciufrpe@gmail.com
} 
normal and rainy scenarios, it was possible to predict times of less probability of crop risk, starting from the determination the onset, duration, and end of each sub-period and the growth of each crop, which are 31/01 to 23/09 and 10/12 to 12/ 09 for cowpea, 31 / 01 to 01/11 and 10/12 to 21/10 for cassava, and 31/01 to 03/10 and 10/12 to 22/09 for corn, in the same order as the precipitation scenarios. There is great variability and irregularity of periods of 10-day rainfall throughout the year in the locations studied.

Keywords: decendial rain; evapotranspiration; phenological cycle; Indians.

\section{INTRODUÇÃO}

Na região nordeste do Brasil existe um grande número de etnias indígenas, das quais, uma parte sobrevive no semiárido nordestino praticando agricultura de subsistência cujos principais cultivos são o milho (Zea mays L.), o feijão-caupi (Vigna unguiculata (L.) Walp.) e a mandioca (Manihot esculenta Crantz) (Albuquerque et al., 2017). Além da lavoura de subsistência, a maior parte da produção agropecuária e extrativista é comercializada em feiras locais e de municípios circunvizinhos.

As comunidades Entre Serras de Pankararu (PE) e Kiriri (BA), de áreas totais, respectivamente, 7.550 e 12.300 ha (Albuquerque et al., 2017), são comunidades indígenas do semiárido nordestino brasileiro, cujo território é demarcado e homologado pelo Órgão Federal Indigenista. São áreas de referência do projeto Gestão Ambiental e Territorial Indígena (GATI) no bioma Caatinga, que objetiva a implementação da Política Nacional de Gestão Territorial e Ambiental de Terras Indígenas (PNGATI), instituída pelo Decreto $n^{\circ}$ 7.747, de 05 de junho de 2012 (Brasil, 2012).

$\mathrm{Na}$ comunidade indígena Entre Serras de Pankararu, 38,88\% da área total correspondem a áreas abertas utilizadas como roçados ou pastagens (Almeida \& Modercin, 2016), enquanto são estimados $44 \%$ do território Kiriri com efetiva ocupação e manejo com atividades agropastoris (Carvalho, 2004). Segundo os dados da Secretaria Especial de Saúde Indígena (Sesai), as populações de índios Pankararu e Kiriri, nesta ordem, contam com 7.644 e 2.344 indígenas.

Nos últimos anos, a frequência e distribuição das chuvas nestas regiões tem se tornado ainda mais irregulares, o que vem comprometendo as atividades agrícolas nos territórios indígenas, tendo em vista que não há colheitas por causa da estiagem em certos períodos (Almeida \& Modercin, 2016). A escassez de chuvas e os longos períodos de estiagem, característicos da região semiárida do nordeste brasileiro, são apontados pelos indígenas como fatores limitantes das atividades agrícolas (Silva \& Santana, 2014).

A região semiárida caracteriza-se pela extrema variabilidade interanual da precipitação pluvial, sendo que, em alguns anos, o suprimento de água às plantas é suficiente para atingir altas produtividades, enquanto, em outros, a deficiência hídrica pode levar à perda total das colheitas (Lima et al., 2011). Essa situação poderá ser agravada pelas mudanças climáticas previstas (Laux et al., 2010).

De acordo com Ayoade (2012), por causa da irregularidade das chuvas, o conhecimento do início e do fim da estação chuvosa contribui para evitar cultivos de lavouras antieconômicos e consequentes prejuízos, que podem provocar situações de calamidade; além de que lavouras cultivadas precocemente serão destruídas, e, por outro lado, as cultivadas tardiamente deixarão de crescer acompanhando o índice ótimo e seu crescimento poderá ser interrompido, quando as chuvas cessarem.

Por causa de as temperaturas serem elevadas, durante todo o ano, nos trópicos, o crescimento das culturas é garantido (exceto em poucas áreas montanhosas); porém, a estação de crescimento passa a ser determinada principalmente pela disponibilidade da precipitação, além de pelo conhecimento e consideração do cultivo das culturas no início do período das chuvas, nas baixas latitudes (Ayoade, 2012).

De acordo com Moura et al. (2008), a demanda hídrica depende, predominantemente, das condições meteorológicas, das características biológicas da espécie cultivada e de seu grau fenológico, além das propriedades físicas do solo. Sendo assim, estudos devem ser realizados para um maior entendimento do comportamento das culturas, em função dos elementos climatológicos, principalmente no caso da condição hídrica para o nordeste do Brasil.

Com o surgimento das previsões climáticas, cuja antecedência pode ser de três a seis meses, para a região do nordeste do Brasil, é possível conhecer o comportamento da precipitação em anos secos, regulares (ou normais) e chuvosos, o que auxiliará no melhor planejamento do plantio e na condução das culturas agrícolas, tendo em vista que a disponibilidade de água, ao longo do ciclo das culturas, é uma variável importante (Moura et al., 2010).

Objetivou-se com este trabalho relacionar as estimativas das condições hídricas com a estação de crescimento e de desenvolvimento de culturas agrícolas importantes para comunidades indígenas do semiárido nordestino brasileiro, considerando-se três distintos cenários climatológicos. 


\section{MATERIAL E MÉTODOS}

A área de estudo é composta por duas áreas de terras indígenas, localizadas no semiárido do nordeste Brasileiro, sendo uma no Estado de Pernambuco e outra no Estado da Bahia. As terras indígenas estudadas foram Entre Serras de Pankararu (situada nos municípios de Jatobá, Petrolândia e Tacaratu, Estado de Pernambuco, mesorregião do São Francisco), e Kiriri (localizada nos municípios de Banzaê e Quijingue, ambos situados no norte do Estado da Bahia) (Figura 1).

Os dados meteorológicos utilizados foram temperatura do ar média mensal e precipitação pluvial diária e mensal (dados consistidos). A série de dados de precipitação pluvial mensal foi correspondente a um período de 28 anos (1963-1990); já a série de dados de temperatura do ar média mensal foi de 80 anos (1911-1990). Estes dados foram obtidos de estações meteorológicas das localidades onde se encontram as terras indígenas estudadas (SUDENE, 1990), Normal Climatológica 1911-1990 disponível na página virtual da Unidade Acadêmica de Ciências Atmosféricas (UACA) da Universidade Federal de Campina Grande (UFCG, 1999).

Ressalta-se que a série de dados utilizada apresenta continuidade no tempo, conforme sugerido pela Organiza- ção Mundial de Meteorologia (OMM), de modo que tenha confiabilidade (cerca de 30 anos). Além disso, as localizações de várias estações pluviométricas foram alteradas após o ano de 1990 (quando a Sudene transferiu a gestão das estações para os Estados), o que não permitiria conseguir a continuidade de tempo sugerida pela OMM. Contudo, a série de dados é muito próxima dos 30 anos e os erros são mínimos.

As mudanças climáticas (ainda em estudo) sugerem, para o final do século (2071 - 2100), alterações na temperatura (por simulações não validadas) de 3,5 a $4,5^{\circ} \mathrm{C}$ e agravamento do déficit hídrico regional, com diminuição de praticamente metade (40 a 50\%) da distribuição de chuva no bioma Caatinga, segundo informações do PBMC (2014). Sendo assim, em relação ao período da coleta dos dados, considera-se que as possíveis mudanças são menos intensas.

As áreas estudadas estão situadas nas coordenadas geográficas representativas de cada localidade: $9,10^{\circ} \mathrm{S}$, $38,15^{\circ} \mathrm{O}$ e altitude de $550 \mathrm{~m}$, para a localidade Jatobá, PE Petrolândia, $\mathrm{PE}$ - Tacaratu, $\mathrm{PE}$, e $10,75^{\circ} \mathrm{S}, 39,20^{\circ} \mathrm{O}$ e altitude de 380 m, para a localidade Banzaê, BA - Quijingue, BA.

Para estimar dados de temperatura média do ar para locais que dispunham apenas de registros de precipitação, foi utilizado o programa computacional Estima_T (ver-

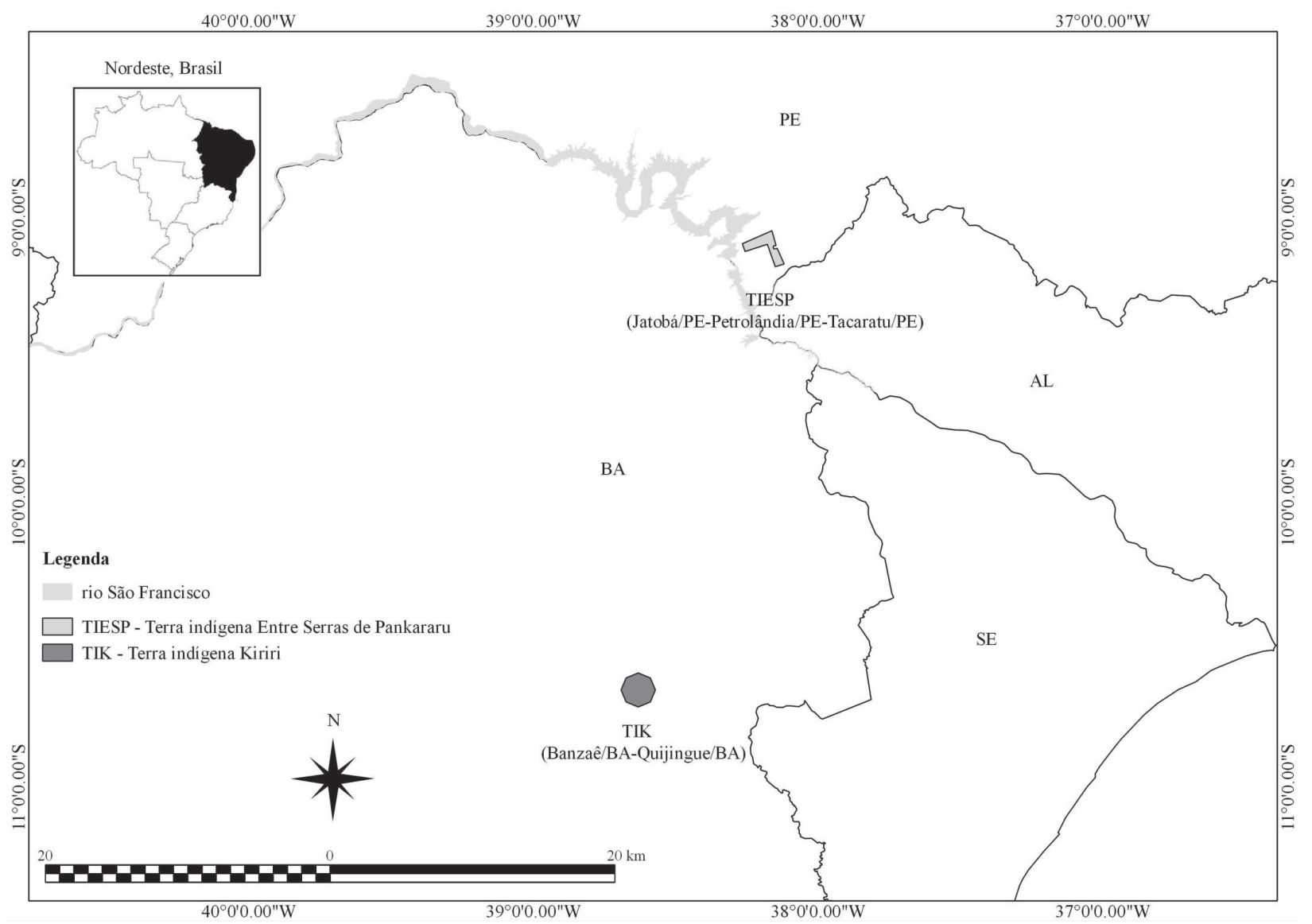

Figura 1: Mapa de localização das terras indígenas nos estados de Pernambuco e da Bahia. 
são 2.0), o qual estima as temperaturas média, máxima e mínima mensais, em função das coordenadas locais longitude, latitude e altitude, desenvolvido por Cavalcanti et al. (2006).

Para o cálculo da evapotranspiração potencial (ETP), foi utilizado o método do balanço hídrico climático (BHC), proposto por Thornthwaite (1948) e descrito por Vianello \& Alves (2013), utilizando-se o software computacional SEVAP (Sistema de Estimativa da Evapotranspiração), desenvolvido na UFCG. Para gerar os balanços hídricos, foram utilizadas as médias mensais das precipitações médias, conforme o cenário pluviométrico, e as médias das temperaturas climatológicas mensais correspondentes, para cada estação meteorológica estudada (por localidade). A capacidade de água disponível no solo (CAD) considerada foi de $100 \mathrm{~mm}$, a qual é utilizada para fins de classificação climática. Os balanços hídricos climáticos foram obtidos, para anos de diferentes totais de precipitações, dividindo-os, de acordo com a ocorrência dos anos secos, regulares (ou normais) e chuvosos, utilizando-se a técnica dos quantis.

Conforme Moura et al. (2010), na avaliação da estação de crescimento, os dados médios diários de precipitação foram acumulados em períodos decendiais para traçar a curva média da precipitação, juntamente com as curvas médias decendiais da evapotranspiração potencial e da metade dessa mesma evapotranspiração, obtendo-se os três subperíodos: pré-úmido (durante o qual a precipitação permanece abaixo da evapotranspiração potencial), úmido (a precipitação média sobrepõe-se à evapotranspiração potencial), e pós-úmido (correspondente a uma redução e final das chuvas (nesse período, a precipitação é superada pela evapotranspiração potencial). Nos meses de 31 dias, considerou-se o último decêndio com 11 dias e, no mês de fevereiro, o último decêndio com oito ou nove dias.

De acordo com o critério adotado por Moura et al. (2010), o início da estação chuvosa e de crescimento corresponde ao dia em que a precipitação média torna-se igual ou superior à metade da evapotranspiração potencial.

O fim da estação de crescimento verifica-se quando a precipitação média torna-se menor que a metade da evapotranspiração potencial mais o intervalo de tempo requerido para retirada de uma lâmina de água correspondente à capacidade de armazenamento do solo.

O final da estação de crescimento foi estimado, partindo-se do princípio de que uma cultura qualquer deva ser irrigada quando se esgotar a fração de CAD, em mm, permissível para que mantenha a condição de evapotranspiração real igual a evapotranspiração máxima da cultura $(\mathrm{ETr}=\mathrm{ETm})$. Nesta condição, o total evapotranspirado $(\mathrm{h})$ atinge o valor $\mathrm{h}=\mathrm{p}$ x CAD, em que $\mathrm{p}$ é a fração de água disponível do solo, abaixo da qual a evapotranspiração real deverá ser menor do que a demanda ideal (ETm). O número de dias (d) no qual esse valor será atingido foi definido pela equação $d=p \times(C A D / E T m)$, em que $\mathrm{p}$ (adimensional) é a fração de água disponível no solo, abaixo da qual a ETr é menor que a ETm $\left(\mathrm{mm} \mathrm{d}^{-1}\right)(\mathrm{ETm}=\mathrm{Kc} \times \mathrm{ETP})$, e foi definido em função do grupo de culturas e respectiva ETm, segundo Doorenbos \& Kassam (1994). A ETm para cada cultura foi calculada utilizando-se os respectivos coeficientes de cultivo $(\mathrm{Kc})$, nas fases de formação, de colheita e de maturação (para o feijão-caupi e o milho, $\mathrm{Kc}=0,95$ e, para a mandioca, Kc =0,30), conforme Doorenbos \& Kassam (1994). O ciclo das culturas, detalhando a duração de cada fase, os coeficientes de cultivo e as demandas hídricas ao longo do seu desenvolvimento, em cada localidade estudada, seguem apresentados na Tabela 1.

\section{RESULTADOS E DISCUSSÃO}

Os suprimentos hídricos das localidades nas quais se encontram as terras indígenas caracterizam-se por ausência de período úmido nos três cenários climatológicos, na localidade Jatobá, PE-Petrolândia, PE-Tacaratu, PE, e no cenário seco na localidade Banzaê, BA-Quijingue, BA, o que torna impossível traçar um planejamento agrícola anual para cultivos de sequeiro nessas localidades, nos respectivos cenários climatológicos, tendo em vista a possibilidade de perdas consideráveis na produtividade das culturas, conforme observações de Lima et al. (2011) e Ayoade (2012). Vale ressaltar que essa precipitação atende às necessidades hídricas da vegetação nativa do bioma Caatinga, que ligeiramente atinge vigor característico logo após as primeiras chuvas.

Apenas para a localidade Banzaê, BA-Quijingue, BA, analisando-se os cenários normal e chuvoso, foi possível prever épocas com menor probabilidade de risco para os cultivos; observou-se a presença de período úmido que apresenta suprimento hídrico além das necessidades das culturas do feijão, da mandioca e do milho, as quais diferem de acordo com a fase fenológica. Esses resultados são corroborados pelas observações feitas por Moura et al. (2008), em que os três cenários apresentaram início distinto para as estações chuvosa e de crescimento, além de o volume precipitado e a duração dos períodos diferirem, em ambos.

O período de desenvolvimento vegetativo das culturas, que é de 40 dias, para o feijão-caupi (Campos et al., 2010); 175 dias, para a mandioca, considerando-se apenas um ciclo vegetativo (Gonzales et al., 2014), e 105 dias, para o milho (Doorenbos \& Kassam, 1994) que é o de maior exigência de água entre esses três cultivos. O suprimento hídrico dar-se-á no subperíodo úmido, o que leva a caracterizar esse período como sendo o da fase de desenvolvimento vegetativo. A partir do subperíodo pós-úmido, as culturas entram na fase de maturação (15 dias, para o feijão-caupi, 180 dias, para a mandioca com um ciclo 
vegetativo e 10 a 15 dias, para o milho) e, por necessitarem de pouca água, coincide com o período de baixa precipitação pluviométrica $(\operatorname{PrP})$.

\section{Localidade Jatobá, PE - Petrolândia, PE - Tacaratu, PE (terra indígena Entre Serras de Pankararu - TIESP)}

Observa-se, na Figura 2, a estação chuvosa da localidade Jatobá, PE-Petrolândia, PE-Tacaratu, PE, em cada cenário climatológico, representada com base na acumulação decendial de precipitação pluviométrica e evapotranspiração potencial.

No cenário seco, a estação chuvosa ocorre entre os meses de março e agosto (início em 20/03 e final em 01/08), cuja duração é de 135 dias, com precipitação pluviométrica de 170,6 mm. Na Figura 2, percebe-se que a evapotranspiração potencial foi sempre superior à precipitação, característica comum e marcante na região do semiárido nordestino brasileiro.

Observa-se uma variação na precipitação pluvial, atingindo picos máximos de 25,0 e 24,3 mm, no nono e décimo segundo decêndios, respectivamente, conforme Figura 2. Nos demais decêndios, observa-se que a precipitação oscila praticamente abaixo da metade da evapotranspiração potencial, exceto no vigésimo primeiro decêndio.

Em relação ao cenário normal, a estação chuvosa nessa localidade tem início em 20/02 e término em 21/07, durando 152 dias, com precipitação pluviométrica de $282,0 \mathrm{~mm}$. No nono decêndio, a precipitação atingiu um pico máximo de $43,65 \mathrm{~mm}$ e, na sequência, atingiu 22,4 e 22,8 mm, no décimo sexto e décimo nono decêndios, respectivamente. No decorrer do tempo, permaneceu praticamente abaixo da metade da evapotranspiração potencial (Figura 2).

Quanto ao cenário chuvoso, nessa localidade, a estação chuvosa ocorre entre os meses de janeiro e agosto (início em 10/01 e final em 01/08), cuja duração é de 204 dias, com precipitação pluviométrica de 646,6 mm. Pela Figura 2 , percebe-se que a precipitação apenas superou a evapotranspiração potencial no quarto decêndio, com 53,7 $\mathrm{mm}$. Em seguida, foi superior novamente no décimo nono, no vigésimo e no vigésimo primeiro decêndios, com precipitações iguais a 28,8; 29,0 e 30,5 mm, respectivamente.

Tabela 1: Ciclo das culturas, detalhando a duração das fases (D), coeficiente de cultivo (Kc) e demanda hídrica (ETm) ao longo do desenvolvimento, em cada localidade estudada

\begin{tabular}{|c|c|c|c|c|c|c|}
\hline \multirow{3}{*}{ Fases do ciclo } & \multicolumn{6}{|l|}{ Cultura } \\
\hline & \multicolumn{3}{|c|}{ Feijão-caupi } & \multicolumn{3}{|c|}{ Milho } \\
\hline & D (dias) & Kc & $\operatorname{ETm}\left(\mathbf{m m ~ d}^{-1}\right)$ & D (dias) & Kc & $\operatorname{ETm}\left(\mathbf{m m ~ d}^{-1}\right)$ \\
\hline \multicolumn{7}{|c|}{ Localidade Jatobá, PE-Petrolândia, PE-Tacaratu, PE } \\
\hline Inicial & $15-20$ & 0,40 & 1,58 & $15-25$ & 0,50 & 1,97 \\
\hline Crescimento & $15-20$ & 0,75 & 2,96 & $25-40$ & 0,85 & 3,36 \\
\hline Intermediário & $20-30$ & 1,05 & 4,15 & $30-45$ & 1,20 & 4,74 \\
\hline Final & $05-20$ & 0,95 & 3,75 & $10-15$ & 0,95 & 3,75 \\
\hline \multicolumn{7}{|c|}{ Localidade Banzaê, BA-Quijingue, BA } \\
\hline Inicial & $15-20$ & 0,40 & 1,53 & $15-25$ & 0,50 & 1,92 \\
\hline Crescimento & $15-20$ & 0,75 & 2,88 & $25-40$ & 0,85 & 3,26 \\
\hline Intermediário & $20-30$ & 1,05 & 4,03 & $30-45$ & 1,20 & 4,60 \\
\hline Final & $05-20$ & 0,95 & 3,64 & $10-15$ & 0,95 & 3,64 \\
\hline \multirow{2}{*}{ Fases do ciclo* } & \multicolumn{6}{|c|}{ Mandioca } \\
\hline & \multicolumn{2}{|c|}{ D (dias) } & \multicolumn{2}{|c|}{ Kc } & \multicolumn{2}{|c|}{$\operatorname{ETm}\left(\mathbf{m m ~ d}^{-1}\right)$} \\
\hline \multicolumn{7}{|c|}{ Localidade Jatobá, PE-Petrolândia, PE-Tacaratu, PE } \\
\hline B & \multicolumn{2}{|c|}{15} & \multicolumn{2}{|c|}{0,30} & \multicolumn{2}{|c|}{1,18} \\
\hline FSR & \multicolumn{2}{|c|}{90} & \multicolumn{2}{|c|}{0,80} & \multicolumn{2}{|c|}{3,16} \\
\hline DPA & \multicolumn{2}{|c|}{70} & \multicolumn{2}{|c|}{0,80} & \multicolumn{2}{|c|}{3,16} \\
\hline ER & \multicolumn{2}{|c|}{90} & \multicolumn{2}{|c|}{0,30} & \multicolumn{2}{|c|}{1,18} \\
\hline \multicolumn{7}{|c|}{ Localidade Banzaê, BA-Quijingue, BA } \\
\hline $\mathrm{B}$ & \multicolumn{2}{|c|}{15} & \multicolumn{2}{|c|}{0,30} & \multicolumn{2}{|c|}{1,15} \\
\hline FSR & \multicolumn{2}{|c|}{90} & \multicolumn{2}{|c|}{0,80} & \multicolumn{2}{|c|}{3,07} \\
\hline DPA & \multicolumn{2}{|c|}{70} & \multicolumn{2}{|c|}{0,80} & & \\
\hline ER & & & 0 , & & & \\
\hline
\end{tabular}

*B - Brotação; FSR - Formação do sistema radicular; DPA - Desenvolvimento da parte aérea; ER - engrossamento das raízes. Fonte: Doorenbos \& Kassam (1994); Gonzales et al. (2014). 


\section{Localidade Banzâe, BA-Quijingue, BA (terra indígena Kiriri - TIK)}

Na Figura 3, observa-se a estação chuvosa da localidade Banzaê, BA-Quijingue, BA, em cada cenário climatológico. Analisando-se os cenários normal (ou regular) e chuvoso, verifica-se que o suprimento hídrico ocorrerá no subperíodo úmido.

Nessa localidade, considerando-se o cenário seco, a estação chuvosa ocorre entre os meses de janeiro e agosto (início em 31/01 e término em 21/08), cuja duração é de 203 dias, com precipitação pluviométrica de $367,8 \mathrm{~mm}$. Na Figura 3, verifica-se que a evapotranspiração potencial foi sempre superior à precipitação, exceto no décimo sétimo decêndio, quando a precipitação atingiu um pico de 31,9 mm e ultrapassou a ETP. Observa-se, ainda, que a precipitação atingiu valores máximos equivalentes a 32,8; 24,0 e 24,4 mm, no décimo terceiro, décimo sexto e vigésimo oitavo decêndios, respectivamente. Essa variabilidade e irregularidade da precipitação, nos primeiros decêndios dos anos secos, também foi verificada por Moura et al. (2008), em pesquisa para determinar o início, a duração e o final de cada período de chuva, além da estação de crescimento da cultura da cana-de-açúcar, em três cenários distintos, para o município de Itambé, PE, região da Mata Norte de Pernambuco.

No cenário normal, a estação de crescimento inicia-se no dia 31/01; para a cultura do feijão-caupi ela vai até o dia 23/09, com 236 dias de duração e 678,6 mm de chuva; para a cultura da mandioca, esta estação termina em 01/11, durando 275 dias e 706,3 mm de precipitação; e, para a cultura do milho, este período tem encerramento na data de $03 / 10$, com 246 dias de duração e 685,6 mm de precipitação pluvial (Tabela 2).

Na Figura 3, é possível observar que há um aumento da precipitação a partir do oitavo decêndio, atingindo o máximo no décimo sexto decêndio, com valor de 44,7 mm. Ao mesmo tempo em que a precipitação aumenta, ocorre diminuição da evapotranspiração potencial em razão do decréscimo natural da temperatura do ar no período úmido.

No subperíodo úmido, com início no dia 11/05, observam-se poucas irregularidades na precipitação, durante todos os decêndios que fazem parte desse subperíodo, que vai até 21/07. Ocorreu máxima precipitação no $16^{\circ}$. decêndio e nos demais decêndios, com variabilidade entre 30 e $41 \mathrm{~mm}$, aproximadamente.

No tempo definido como o subperíodo pós-úmido, também ocorreu pouca variabilidade na precipitação pluviométrica; todavia, essa variabilidade é comum na região nordeste do Brasil, segundo Vianello \& Alves (2013) e Silva et al. (2011). As durações dos subperíodos pré-úmido, úmido e pós-úmido foram de 100, 72 e 42 dias, respectivamente, conforme Tabela 2. As precipitações correspondentes aos subperíodos pré-úmido, úmido e pós-úmido foram 295,0; 271,5 e 78,4 mm, respectivamente.

No cenário chuvoso, a estação de crescimento iniciase no dia 10/12; para a cultura do feijão-caupi, a estação de
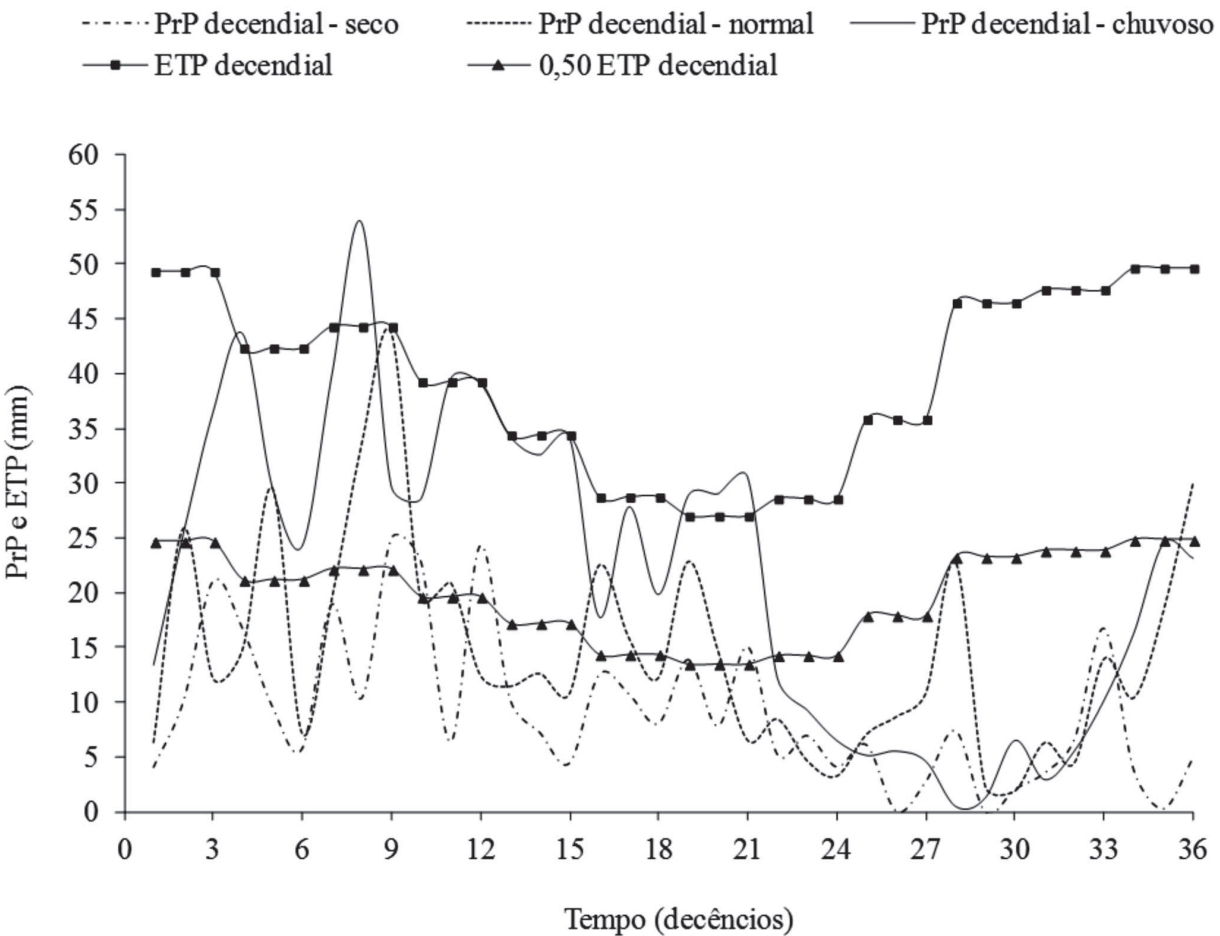

Figura 2: Estação chuvosa de Jatobá, PE-Petrolândia, PE-Tacaratu,PE, representação com base no acúmulo decendial da precipitação pluviométrica e evapotranspiração potencial nos cenários seco, normal e chuvoso, no período 1963-1990. 
crescimento vai até o dia 12/09 do ano seguinte, com 277 dias de duração e 1.437,0 mm de chuva; em relação à cultura da mandioca, a estação de crescimento termina em 21/ 10, durando 316 dias e 1.464,3 mm de precipitação, e para a cultura do milho, a estação de crescimento tem encerramento na data de 21/08, com 287 dias de duração e 1.437,9 mm de precipitação pluvial (Tabela 3 ).

Estes dados de precipitação são semelhantes aos encontrados por Moura et al. (2010), em pesquisa com a cultura da cana-de-açúcar para o município de Ipojuca, PE (região Metropolitana), com exceção do volume precipitado no cenário chuvoso, observado por aqueles autores, que foi de $2.578 \mathrm{~mm}$; quanto à duração do ciclo vegetativo, aqueles autores encontraram dados inferiores, que variaram de 229; 236 e 267 dias para os cenários seco, normal e chuvoso, respectivamente.

Na Figura 3, é possível observar que a precipitação superou a evapotranspiração a partir do sétimo decêndio, chegando ao máximo no $14^{\circ}$. decêndio, com valor de 146,8 mm. Ao mesmo tempo em que a precipita-

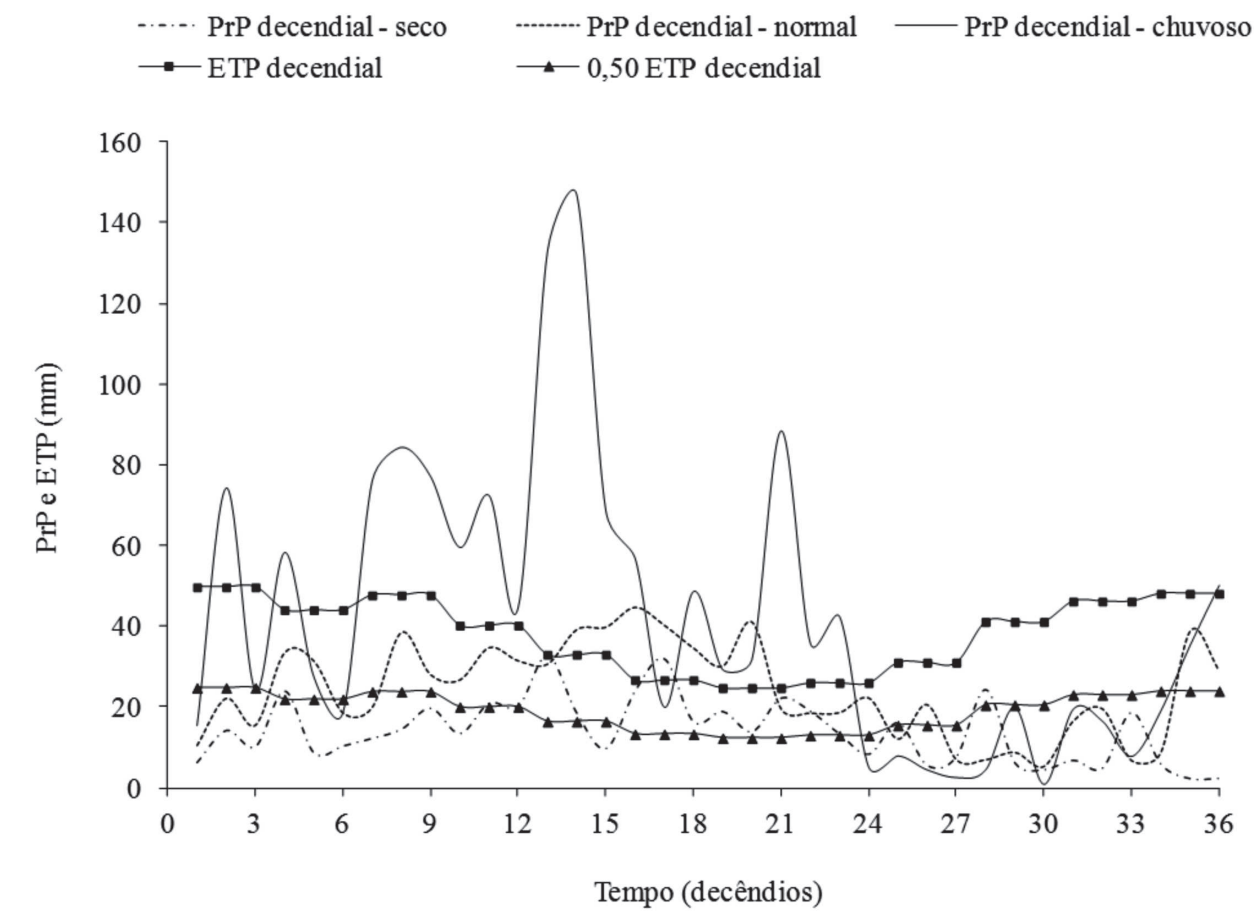

Figura 3: Estação chuvosa de Banzaê, BA-Quijingue, BA, representação com base no acúmulo decendial da precipitação pluviométrica e evapotranspiração potencial nos cenários seco, normal e chuvoso, no período 1963-1990.

Tabela 2: Característica do cenário normal na estação de crescimento de Banzaê, BA-Quijingue, BA, para as culturas do feijão-caupi, da mandioca e do milho em função da precipitação pluviométrica e evapotranspiração potencial para o período de 1963 a 1990

\begin{tabular}{lccccccc}
\hline \multirow{2}{*}{ Plantio } & \multicolumn{3}{c}{ Estação de Crescimento } & \multirow{2}{*}{ Estação chuvosa } & Pré-úmido & \multirow{2}{*}{ Úmido } & \multirow{2}{*}{ Pós-úmido } \\
\cline { 2 - 4 } & Feijão & Mandioca & Milho & & & & \\
\hline Início & $31 / 01$ & $31 / 01$ & $31 / 01$ & $31 / 01$ & $31 / 01$ & $11 / 05$ & $22 / 07$ \\
Término & $23 / 09$ & $01 / 11$ & $03 / 10$ & $01 / 09$ & $10 / 05$ & $21 / 07$ & $01 / 09$ \\
Duração (dias) & 236 & 275 & 246 & 214 & 100 & 72 & 42 \\
PrP (mm) & 678,6 & 706,3 & 685,6 & 644,9 & 295,0 & 271,5 & 78,4 \\
\hline
\end{tabular}

Tabela 3: Característica do cenário chuvoso na estação de crescimento de Banzaê, BA-Quijingue, BA, para as culturas do feijão-caupi, da mandioca e do milho em função da precipitação pluviométrica e evapotranspiração potencial para o período de 1963 a 1990

\begin{tabular}{|c|c|c|c|c|c|c|c|}
\hline \multirow{2}{*}{ Plantio } & \multicolumn{3}{|c|}{ Estação deCrescimento } & \multirow{2}{*}{ - Estação chuvosa } & \multirow{2}{*}{ Pré-úmido } & \multirow{2}{*}{ Úmido } & \multirow{2}{*}{ Pós-úmido } \\
\hline & Feijão & Mandioca & Milho & & & & \\
\hline Início & $10 / 12$ & $10 / 12$ & $10 / 12$ & $10 / 12$ & $10 / 12$ & $01 / 03$ & $12 / 06$ \\
\hline Término & $12 / 09$ & $21 / 10$ & $22 / 09$ & $21 / 08$ & $28 / 02$ & $11 / 06$ & $21 / 08$ \\
\hline Duração (dias) & 277 & 316 & 287 & 255 & 81 & 103 & 71 \\
\hline $\operatorname{PrP}(\mathrm{mm})$ & $1.437,0$ & $1.464,3$ & $1.437,9$ & $1.420,5$ & 305,3 & 820,9 & 294,3 \\
\hline
\end{tabular}


ção aumenta, ocorre diminuição da evapotranspiração potencial, pela diminuição natural da temperatura do ar no período úmido.

No subperíodo úmido, com início no dia 01/03, observa-se grande irregularidade na precipitação, durante todos os decêndios que fazem parte desse subperíodo, que vai até $11 / 06$, o mesmo observado por Polzin \& Hastenrath (2014), no norte do nordeste do Brasil, área em que a estação das chuvas é concentrada em torno dos meses de março, abril e maio. Ocorreu uma máxima precipitação no $14^{\circ}$. decêndio e nos demais decêndios, com uma variabilidade entre 20,0 e $88,4 \mathrm{~mm}$, aproximadamente.

No tempo entendido como o subperíodo pós-úmido, também ocorreu grande variação da precipitação pluviométrica. As durações dos subperíodos pré-úmido, úmido e pós-úmido foram de 81, 103 e 71 dias, respectivamente, conforme Tabela 3. As precipitações foram iguais a 305,3; 820,9 e 294,3 mm, nos subperíodos pré-úmido, úmido e pós-úmido, respectivamente.

Verifica-se que a estação de crescimento, nos cenários normal e chuvoso, apresenta demanda hídrica satisfatória, apresentando adequadas condições para o desenvolvimento vegetativo das culturas, sendo, portanto, a melhor época de semeadura; pode ser observado, ainda, que, mesmo nos subperíodos pré-úmido e pós-úmido, existe uma adequada precipitação em relação à quantidade de dias, implicando ausência de deficiência hídrica no início ou no final do ciclo das culturas, desde que seja planejada a data de plantio.

Doorenbos \& Kassam (1994) citam que a ocorrência de períodos de déficit hídrico durante as fases de maior sensibilidade das culturas (emergência, floração e fase inicial de formação da colheita) provoca efeitos bastante variados sobre o rendimento, a depender do grau de sensibilidade da cultura (espécie, variedade, intensidade e duração do déficit hídrico).

Pela análise das condições hídricas das localidades em estudo, é possível verificar a variabilidade e irregularidade da precipitação pluviométrica, inerentes ao clima semiárido. Observa-se que, em anos normais e chuvosos, para a localidade Banzaê, BA-Quijingue, BA, as estações chuvosas apresentaram variações no seu início, em volume precipitado e em durações em dias, confirmando as observações de Silva et al. (2011), quando afirmam que a região do semiárido nordestino apresenta os maiores valores de coeficiente de variação da precipitação pluvial e do número de dias de chuva.

De posse desse conhecimento, e de acordo com Ayoade (2012), é possível organizar os plantios de modo que a estação chuvosa coincida com o período de maior demanda das culturas, fornecendo as quantidades de água necessárias para o desenvolvimento vegetativo.

\section{CONCLUSÕES}

Na região do semiárido nordestino brasileiro, não é possível traçar um planejamento anual agrícola para cultivos de sequeiro em cenários de anos secos.

Há uma grande variabilidade e irregularidade de períodos de dez dias de precipitação, ao longo do ano, nas localidades estudadas.

Apenas para a localidade de Banzaê, BA-Quijingue, BA, nos cenários normal e chuvoso, foi possível prever épocas com menor probabilidade de risco para os cultivos, a partir da determinação do início, da duração e do final de cada subperíodo, bem como da estação de crescimento de cada cultura, que são 31/01 a 23/09 e 10/12 a 12/ 09 para o feijão-caupi, 31/01 a 01/11 e 10/12 a 21/10 para a mandioca, e 31/01 a 03/10 e 10/12 a 22/09 para o milho, na mesma ordem dos cenários de precipitação.

\section{REFERÊNCIAS}

Albuquerque F da S, Silva EF de F e, Lopes PMO, Moura GB de A, Silva BB da \& Barros AHC (2017) Aptidão climática de culturas agrícolas importantes para comunidades indígenas do semiárido brasileiro. Irriga, 22:59-73.

Almeida EA de \& Modercin IF (2016) Etnomapeamento da Terra Indígena Entre Serras de Pankararu. Salvador, Anaí. 63p.

Ayoade JO (2012) Introdução à climatologia para os trópicos. $16^{\mathrm{a}}$ ed. Rio de Janeiro, Bertrand Brasil. 332p.

Brasil (2012) Decreto $\mathrm{n}^{\mathrm{o}}$ 7.747, de 05 de junho de 2012. Institui a Política Nacional de Gestão Territorial e Ambiental de Terras Indígenas - PNGATI. DOU, 06/06/2012, Seção 1, p.09.

Campos JHB da C, Silva MT \& Silva V de PR da (2010) Impacto do aquecimento global no cultivo do feijão-caupi, no Estado da Paraíba. Revista Brasileira de Engenharia Agrícola e Ambiental, 14:396-404.

Carvalho AM (2004) Gestão ambiental Kiriri: etnografia, história e ambiente. Dissertação de Mestrado. Universidade Federal da Bahia, Salvador. 128p.

Cavalcanti EP, Silva V de PR da \& Sousa FAS (2006) Programa computacional para estimativa da temperatura do ar para a Região Nordeste do Brasil. Revista Brasileira de Engenharia Agrícola e Ambiental, 10:140-147.

Doorenbos J \& Kassam AH (1994) Efeito da água no rendimento das culturas. Campina Grande, UFPB. 306p. (Estudos FAO: Irrigação e Drenagem, 33).

Gonzales PF, Bicudo SJ, Moraes-Dallaqua MA, Tanamati FY \& Aguiar EB (2014) Componentes de produção e morfologia de raízes de mandioca sob diferentes preparos do solo. Bragantia, $73: 357-364$

Laux P, Jäckel G, Tingem RM \& Kunstmann H (2010) Impact of climate change on agricultural productivity under rainfed conditions in Cameroon - A method to improve attainable crop yields by planting date adaptations. Agricultural and Forest Meteorology, 150:1258-1271.

Lima JR de S, Antonino ACD, Lira CAB de O, Souza ES de \& Silva I de F da (2011) Balanço de energia e evapotranspiração de feijão caupi sob condições de sequeiro. Revista Ciência Agronômica, 42:65-74 
Moura GB de A, Bastos GQ, Giongo PR, Lopes PMO \& Medeiros SRR de (2010) Estimativas das condições hídricas em Ipojuca, região canavieira de Pernambuco. Revista Caatinga, 23:71-76.

Moura GB de A, Melo JSP de, Giongo PR, Lira Júnior M de A \& Silva APN da (2008) Relação entre condições hídricas e o crescimento vegetal da cana-de-açúcar no município Itambé, Pernambuco. Revista Caatinga, 21:171-177.

PBMC - Painel Brasileiro das Mudanças Climáticas (2014) Base Científica das Mudanças Climáticas. Volume 1 - Primeiro Relatório de Avaliação Nacional. Rio de Janeiro, Universidade Federal do Rio de Janeiro. 351p.

Polzin D \& Hastenrath S (2014) Climate of Brazil's northeast and tropical atlantic sector: Preferred time scales of variability. Revista Brasileira de Meteorologia, 29:153-160.

Silva VPR da, Pereira ERR, Azevedo PV de, Sousa F de AS de \& Sousa IF de (2011) Análise da pluviometria e dias chuvosos na região Nordeste do Brasil. Revista Brasileira de Engenharia Agrícola e Ambiental, 15:131-138.
Silva YV da \& Santana SEL (2014) Conhecendo realidades expressão de comunidades indígenas dos Estados da Bahia e Pernambuco sobre suas realidades. Paulo Afonso, Fonte Viva. $160 \mathrm{p}$.

SUDENE - Superintendência do Desenvolvimento do Nordeste (1990) Dados pluviométricos mensais do Nordeste. Série Pluviometria 1 a 10. Recife, SUDENE. 2.134p.

Thornthwaite CW (1948) An approach toward a rational classification of climate. Geographical Review, 38:55-94.

UFCG - Universidade Federal de Campina Grande (1999) Normais Climatológicas da Área da SUDENE. Disponível em: <http://www.dca.ufcg.edu.br/tsm.htm>. Acessado em: 03 de março de 2014.

Vianello RL \& Alves AR (2013) Meteorologia básica e aplicações. $2^{\mathrm{a}}$ ed. Viçosa, UFV. 460p. 